\title{
How John Parkinson did the post mortem on Sir James Mackenzie
}

Department of Medicine, University College London Medical School, London

A Hollman

Correspondence to: Dr A Hollman, Department of Medicine, University College London Medical School, 5 University Street, London WC1E 6JJ.

Accepted for publication 14 September 1993.

Figure 1 fohn Parkinson (1885-1976) aged 44.

Arthur Hollman

In the 1950s Sir John Parkinson (fig 1) was the doyen of British cardiology and known worldwide especially for the Wolff-ParkinsonWhite syndrome. His seniority was combined with a concern for the younger members of the specialty and it was his custom to invite the Junior Cardiac Club to his home. ${ }^{1}$ That is how he recognised me one afternoon in June 1954 when I was walking to the National Heart Hospital to attend Dr Paul Wood's clinic. I said that I was going to show Dr Wood the heart of a patient of his who had died at University College Hospital. Sir John asked jokingly if the leather case in my hand was my portable postmortem set, and he then invited me to see his own such set. The next day I went to his rooms where he got out the set and told me its history.

When he was chief assistant to Dr (later Sir) James Mackenzie at the London Hospital in 1913 he was encouraged to purchase a small postmortem set because it was, said Mackenzie, very useful for doing post mortems in peoples' homes. We can safely

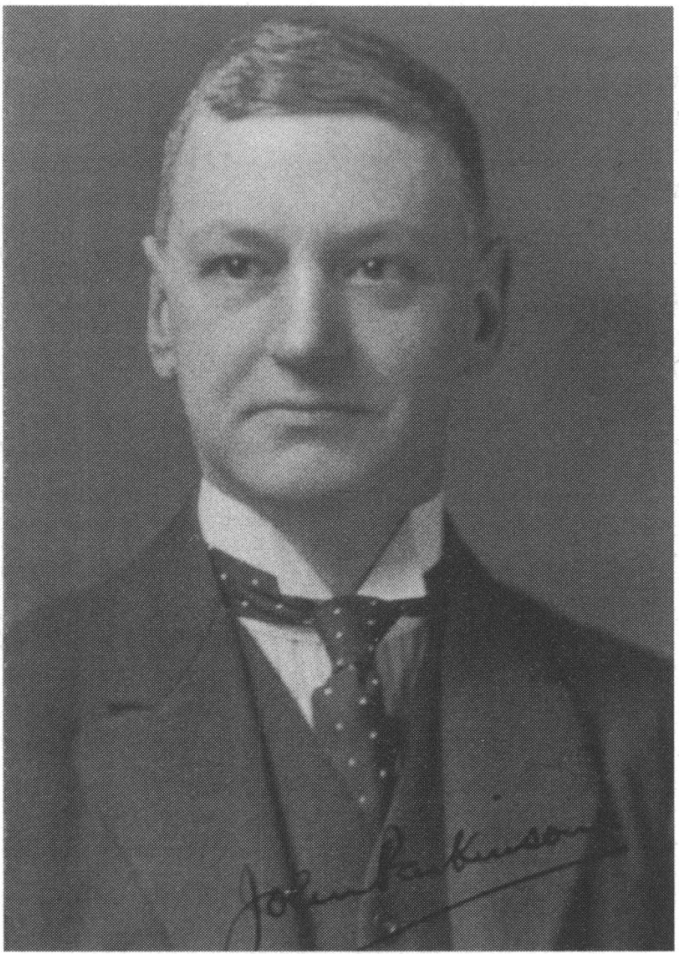

assume from this first hand comment that this was what Mackenzie did when he was in general practice in Burnley, though there is no mention of such post mortems in his obituaries and biographies..$^{2-6}$ It is a great tribute to Mackenzie's standing in the community-"the beloved physician"-that he was able to do so. Certainly he sent hearts to Dr (later Sir) Arthur Keith for pathological examination having written, ${ }^{7}$ "You are the man I have been looking for; I have hearts which I observed in patients over a long series of years and now I want some one to examine them." They came from patients with heart block and with atrial fibrillation ${ }^{8}$ and were examined before Keith and Flack discovered the sino-atrial node.

The set that Sir John Parkinson showed me (fig 2) was in a mahogany case measuring $32 \times 16 \times 6 \mathrm{~cm}$ and weighing $1.9 \mathrm{~kg}$. It was in excellent condition and contained a saw, a spine wrench, bowel scissors, a large knife, scalpels, a hammer, scissors, and hooks. Many of these items were stamped Evans and Co. Old Change-an address near the London Hospital. It was a typical postmortem set of the time. Similar ones are illustrated in the catalogue of Down Brothers for 1906 which lists 13 sets of varying content, costing between $£ 2.0$ s.0d and $£ 10.8$ s.0d (say $£ 120$ to $£ 650$ now). In three of them the instruments were in a metal tray so that they could be sterilised.

Sir James Mackenzie's own cardiac problems began when he was 47 and atrial fibrillation developed after he had run 400 yards. At the age of 54 slight angina of effort developed and the next year, 1908, he had a two hour attack of cardiac pain during the night. After that his angina slowly worsened but he was 68 before it forced him to give up his beloved golf. A few weeks before his death at the age of 72 Mackenzie told Parkinson that he was to do a postmortem examination when the time came: "I protested, but he smiled and said that his brother (the late Lord Amulree) would see that I did what he wished". ${ }^{9}$ By now Mackenzie had to chew a trinitrin tablet even before leaving his study to greet a visitor. This did not prevent him, a true Scot, from attending the Burns Night celebration in 1925. However, severe cardiac pain during the evening forced him to return to his flat in Albert Hall Mansions. During that night and 
Figure 2 Sir fohn Parkinson's postmortem set.

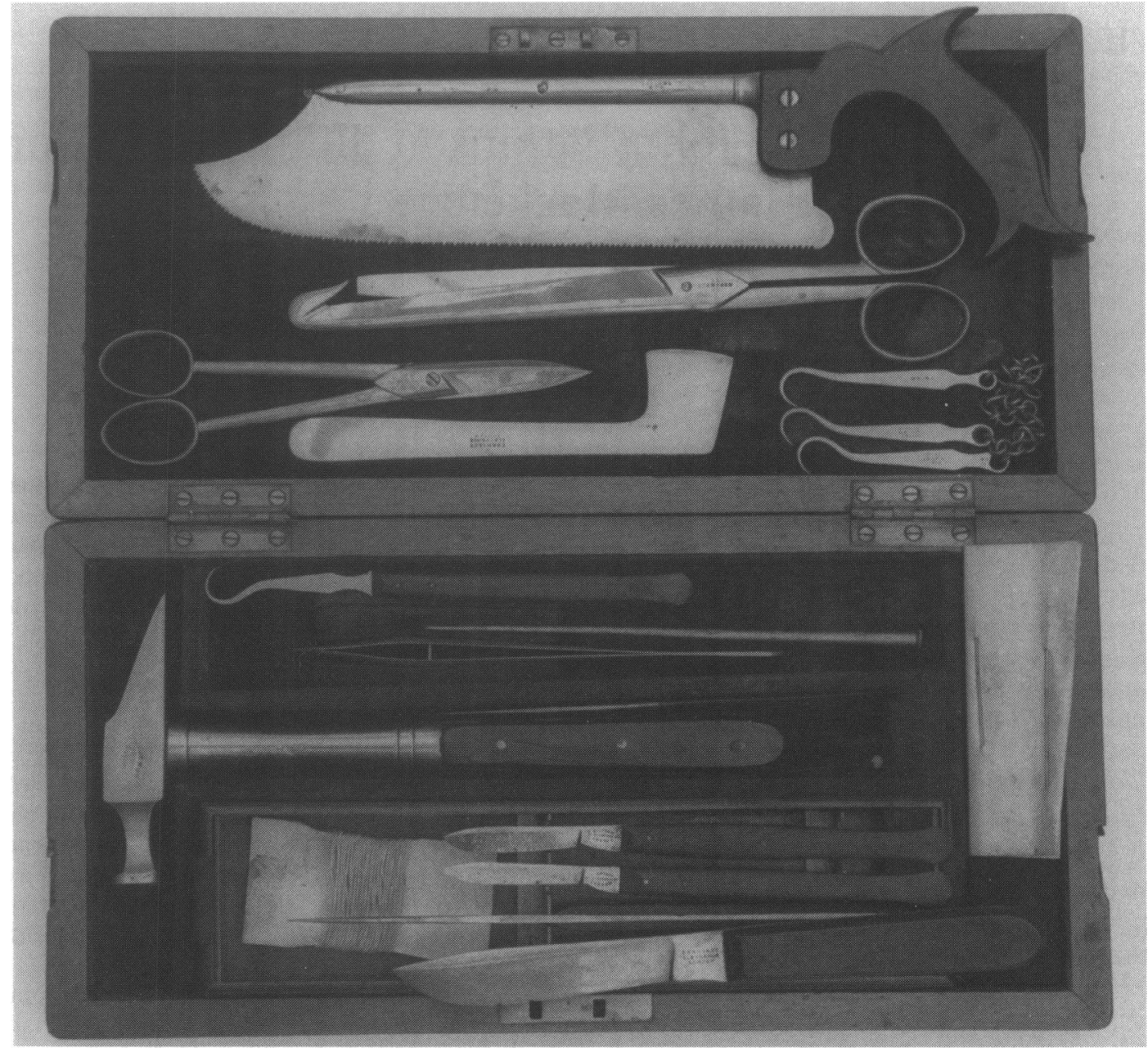

the following day he was given chloroform inhalations and morphine to alleviate severe and prolonged attacks of pain and he died at 4 am on January 26 (30 hours after the onset of pain). Parkinson then used his postmortem set, possibly for the first time. The examination was made 14 hours after death so it may have been done elsewhere than in the flat. As he did the examination Parkinson must have remembered, among many other reflections, the day 12 years before when his chief had advised him to buy a postmortem set. He removed the heart and sent it to Professor David Waterston who was professor of anatomy at St Andrews University where Mackenzie had founded his Institute for Clinical Research in 1917.

In $1932 \mathrm{Sir}$ Thomas Lewis asked Waterston if he might be allowed to examine his "old friend's" heart (Wellcome Institute. Contemporary Medical Archives Centre, PP/LEW A1/723) and he did so with his assistant Dr R T Grant. Their report is incorporated in Waterston's article "Sir James Mackenzie's heart" which appeared in the first volume of the British Heart fournal in 1939. ${ }^{10}$ In brief there was severe coronary atheroma with an old infarct that was consistent with the episode in 1908 and also a recent infarct together with numerous small scars in the left ventricle. A mass of thrombus, mostly recent, overlay an area of severe subendocardial fibrosis.

1 Campbell M. The British Cardiac Society and the Cardiac Club: 1922-1961. Br Heart f 1962;24:673-95. biography. London: John Murray, 1926.

3 Mair A. Sir Fames Mackenzie, M.D. 1853-1925, General

4 Obituary. Sir James Mackenzie. Br Med f 1925;i:242-4.

5 Obituary. Sir James Mackenzie. Lancet 1925;i:257-9.

6 Lewis T. In memoriam. Sir James Mackenzie. Hear 1925;25:i-iv:

7 Keith A. An autobiography. London: Watts and $\mathrm{Co}_{\text {, }}$ 1950:253-5.

8 Mackenzie J. New methods of studying affections of the heart. IV. Action of digitalis on the human heart in cases where the inception of the rhythm of the heart is due to the ventricle. Br Med $\mathcal{F} 1905$; i:759-62.

9 Parkinson J. Sir James Mackenzie. The centenary of his birth. Br Heart $¥$ 1954;15:125-7.

10 Waterston D. Sir James Mackenzie's heart. Br Heart 1939;1:237-48.
2 Wilson JM. The beloved physician, Sir fames Mackenzie: a Practitioner. Edinburgh: Churchill Livingstone, 1973. 